This item was submitted to Loughborough's Research Repository by the author.

Items in Figshare are protected by copyright, with all rights reserved, unless otherwise indicated.

\title{
Real-time energy management for diesel heavy duty hybrid electric vehicles
}

PLEASE CITE THE PUBLISHED VERSION

http://dx.doi.org/10.1109/TCST.2014.2343939

\section{PUBLISHER}

(c) IEEE

\section{VERSION}

VoR (Version of Record)

\section{PUBLISHER STATEMENT}

This work is made available according to the conditions of the Creative Commons Attribution-NonCommercialNoDerivatives 4.0 International (CC BY-NC-ND 4.0) licence. Full details of this licence are available at: https://creativecommons.org/licenses/by-nc-nd/4.0/

\section{LICENCE}

CC BY-NC-ND 4.0

\section{REPOSITORY RECORD}

Zhao, Dezong, Richard Stobart, Guangyu Dong, and Edward Winward. 2014. "Real-time Energy Management for Diesel Heavy Duty Hybrid Electric Vehicles". Loughborough University. https://hdl.handle.net/2134/26511. 


\title{
Real-Time Energy Management for Diesel Heavy Duty Hybrid Electric Vehicles
}

\author{
Dezong Zhao, Member, IEEE, Richard Stobart, Member, IEEE, Guangyu Dong, and Edward Winward
}

\begin{abstract}
In this paper, a fuzzy tuned equivalent consumption minimization strategy (F-ECMS) is proposed as an intelligent real-time energy management solution for a conceptual diesel engine-equipped heavy duty hybrid electric vehicle (HEV). In the HEV, two electric motors/generators (EMGs) are mounted on the turbocharger shaft and engine shaft respectively, which can improve fuel efficiency by capturing and storing energy from both regenerative braking and otherwise wasted engine exhaust gas. The heavy duty HEV frequently involved in duty cycles characterized by start-stop events, especially in off-road applications, whose dynamics is analysed in this paper. The on-line optimization problem is formulated as minimizing a cost function in terms of weighted fuel power and electric power. In the cost function, a cost factor is defined for both improving energy transmission efficiency and maintaining the battery energy balance. To deal with the non-explicit relationship between HEV fuel economy, battery state-of-charge (SOC) and control variables, the cost factor is fuzzy tuned using expert knowledge and experience. In relation to the fuel economy, the air-fuel ratio (AFR) is an important factor. An on-line search for capable optimal variable geometry turbocharger (VGT) vane opening and exhaust gas recirculation (EGR) valve opening is also necessary. Considering the exhaust emissions regulation in diesel engine control, the boundary values of VGT and EGR actuators are identified by off-line design-of-experiment (DOE) tests. An on-line rolling method is used to implement the multi-variable optimization. The proposed method is validated via simulation under two transient driving cycles, with the fuel economy benefits of $4.43 \%$ and $6.44 \%$ over the non-hybrid mode, respectively. Comparing with the telemetry ECMS (T-ECMS), the proposed FECMS shows better performance in the sustainability of battery SOC under driving conditions with the rapid dynamics often associated with off-road applications.
\end{abstract}

Index Terms-Hybrid electric vehicles, heavy duty diesel engines, energy management, on-line optimization, fuel economy benefits

\section{INTRODUCTION}

$\mathbf{T}$ HE White House announced new fuel efficiency standards for trucks, buses, and other heavy duty vehicles in August 2011. Within the standards, vehicles manufactured between 2014 and 2018 are required to reduce their fuel consumption and greenhouse gas emissions by between $10 \%$

Manuscript received January 21, 2013; revised August 11, 2013, February 6, 2014, and May 9, 2014; accepted June 29, 2014. This work was supported by grant funding from the U.K.'s innovation agency, the Technology Strategy Board, through its Collaborative Research and Development Programme

D. Zhao, R. Stobart, and E. Winward are with the Department of Aeronautical and Automotive Engineering, Loughborough University, Loughborough LE11 3TU, U.K. (e-mail: d.zhao2@lboro.ac.uk, r.k.stobart@lboro.ac.uk, r.e.t.b.winward@1boro.ac.uk).

G. Dong is with the School of Computing, Engineering and Mathematics, University of Brighton, Brighton BN2 4GJ, U.K. (e-mail: g.dong@brighton.ac.uk). to $20 \%$ [1]. HEVs are considered as one of the solutions to reducing fuel consumption [2], [3]. By exploiting the capacity of a storage system installed aboard, HEVs can achieve better fuel economy and lower exhaust emissions than traditional powertrain vehicles. In an HEV, an electrical path is added on the powertrain such that part of the vehicle kinetic energy and exhaust gas energy can be captured by the electrical machines, and used to recharge the battery. The energy provided by the electrical machines also helps downsizing the internal combustion engine (ICE), resulting in better fuel efficiency and lower heat loss than entirely mechanical systems [4]. Since electrical machines provide faster boosting torque, HEVs offer improved launch performance and reduced overall rated power compared with traditional ICE vehicles. According to the powertrain topologies, HEVs can be divided into three categories [5]: parallel [6], [7], series [8], [9], and powersplit [10]-[13]. As a combination of parallel and series HEVs, power-split HEVs enjoy the benefits of parallel and series characteristics. Therefore, the power-split configurations are preferred for commercially available hybrid powertrains, such as the Ford Escape Hybrid and the Toyota Prius.

A key issue in developing $\mathrm{HEV}_{\mathrm{s}}$ is the coordination of multiple energy flows in respectively the fuel path and the electrical path. The target of the management of power distribution in the parallel paths is to minimize the fuel consumption, while maintaining the battery SOC within reasonable limits [14]. The HEV control can be fulfilled in a two-level hierarchical structure: a supervisory level control in managing the energy flow, and a lower level control in regulating performance variables [15]. The supervisory control strategies can be grouped into three categories: rule-based control strategies, numerical optimization-based control strategies, and real-time optimization strategies.

The rule-based control strategies can be easily implemented in real-world vehicles, such as the bang-bang control [16], [17], fuzzy logic [18]-[20], and neural networks [21], [22]. The rules are designed using heuristics, human expertise, or mathematical models. Although the control approaches can offer improvement in energy efficiency, it is clear that they do not guarantee an optimal result in all conditions. As a brief discussion of fuzzy logic control strategies in HEV, [18] used the fuzzy logic to tune the PI controller to achieve a smoother performance, but did not consider the rapid changing road dynamics; [19] focused on battery SOC management but took neither emissions nor engine efficiency into account; [20] is capable to maintain the battery SOC in a reasonable range, rather than achieving the demand value at the end of the test cycle. 
The numerical optimization-based control strategies mainly include dynamic programming [23]-[25], stochastic programming [26], [27], and linear programming [28], which can find a global optimum solution by performing the optimization over a prescribed drive cycle. Unfortunately, the global optimization approach is non-causal in nature, because it requires a prior knowledge of the future driving information. The global optimization schemes cannot offer an on-line solution, but can be treated as a benchmark to evaluate the performance of the rulebased control methods. The real-time optimization strategies manage the energy flow on-line, where the most well-known approach is the equivalent consumption minimization strategy (ECMS) [29]-[34].

The ECMS realizes the optimization problem by minimizing an instantaneous cost function, so behaves as a closed-loop controller. If the vehicle velocity profile is a priori, the online power flow solution would be near-optimal [25]. However, in real time implementations, only past and limited future information are available. Therefore, the ECMS is normally an applicable strategy to optimizing fuel economy using local information. To improve the fuel economy optimization performance, the ECMS can be applied with model predictive control (MPC) methods to make a preview of the future driving conditions in a finite horizon [35]-[39]. The equivalent fuel consumption is defined as the combination of the engine fuel consumption and an additional fuel consumption proportional to the energy discharged from the battery under the management of the supervisory control. The battery SOC is a tough constraint on battery sustainable usage and requires proper management of the energy flow to and from the battery [40].

Diesel HEVs have gained significant interest globally due to the high thermal efficiency of diesel engines, and are of increasing interest in heavy duty vehicles in off-road applications. However, there is a trade-off in diesel engines between the efficiency and further reduction of exhaust emissions such as nitrogen oxides $\left(\mathrm{NO}_{x}\right)$ and particulate matter (PM). The increasingly tight pollution standards have increased the air system complexity of diesel engine with many now being equipped with both a VGT and an EGR valve [41]. Turbocharging the diesel engine reduces fuel consumption, and together with the EGR enables a reduction in exhaust emissions, in particular $\mathrm{NO}_{x}$ [42]. The regulation of VGT and EGR actuators impacts the AFR value, which is an important factor in managing the fuel economy and exhaust emissions. Therefore, finding capable optimal setpoints of VGT and EGR actuators is beneficial in reducing the fuel consumption, while satisfying the legislation on exhaust emissions [43]-[46]. A very appealing research approach in dealing with the emission constraints is considering both emissions and vehicle thermaldynamic characteristics in control, which is referred as the integrated powertrain control [47]-[49].

In this paper, a supervisory control algorithm is proposed for real-time energy management to find the applicable values of power distribution, VGT vane opening, and EGR valve opening simultaneously for the diesel engine-equipped heavy duty HEV. The HEV is a conceptual vehicle designed for a heavy haul duty with frequent start-stop operation. In the HEV, an electric motor is mounted on the turbocharger shaft while another one is integrated on the engine shaft. The configuration can improve fuel efficiency by capturing and storing energy from both regenerative braking and otherwise wasted engine exhaust gas. Furthermore, the air path dynamics can also be accelerated by boosting intake manifold pressure to enhance the engine torque. Fuel economy is of prime concern and as a consequence the cost function for the operation of the vehicle combines fuel economy and emissions control. A realtime cost function is defined with weighted fuel power and electrical power, and the optimization of the control variables is formulated as minimizing the cost function. Considering the nonlinearities and mechanical constraints existing in the HEV powertrain and engine air path, it is challenging to find the set of optimal control variables to optimize the fuel economy in real time. For the investigated diesel HEV, the set of control variables includes the power of the two mounted electric motors, VGT vane opening, and EGR valve opening. In the proposed strategy, a fuzzy rule-based method is applied to tuning the cost factor defined in the cost function, to deal with the non-quantitative measures. The fuzzy tuning method combines the expert human knowledge and experience using comprehensible linguistic rules to control the diesel HEV in complicated driving cycles with fast dynamics. An online rolling method is used to implement the multi-variable optimization. Considering the exhaust emission regulation, the margin values of diesel engine air path actuators are restricted in allowed ranges, which are identified according to off-line DOE tests.

This paper is organized as follows: section I - the introduction; section II - the models of the heavy duty HEV powertrain system and the diesel engine air path are given; section III the optimization problem is formulated; section IV - the FECMS algorithm is presented; section $\mathrm{V}$ - validations of the algorithm are demonstrated; and section VI - the conclusions are summarized.

\section{Heavy Duty Diesel HEV Model}

The schematic of the conceptual diesel engine-equipped heavy duty HEV is shown in Fig. 1. A heavy duty diesel engine installed on a chassis is used as the test platform. The diesel engine consists of a turbocharger with an EMG (EMG 1) mounted on the turbocharger shaft, and another EMG (EMG 2) mounted on the engine crankshaft. When the power produced by the turbocharger exceeds the power requirement of the compressor, the surplus mechanical power is converted into electrical power by EMG 1, and is stored in the battery. In the case where the power requirement of the compressor cannot be met, EMG 1 is used as a motor to accelerate the turbocharger shaft. Similarly, EMG 2 either behaves as a motor to assist the engine, or behaves as a generator to recover the braking energy into the battery in the regeneration mode. The power flow in the HEV starts with the fuel in the tank being supplied to the diesel engine, then the generated power is transmitted to the gearbox to drive the vehicle. The HEV is driven by the power through both of the fuel path and the electrical path. 


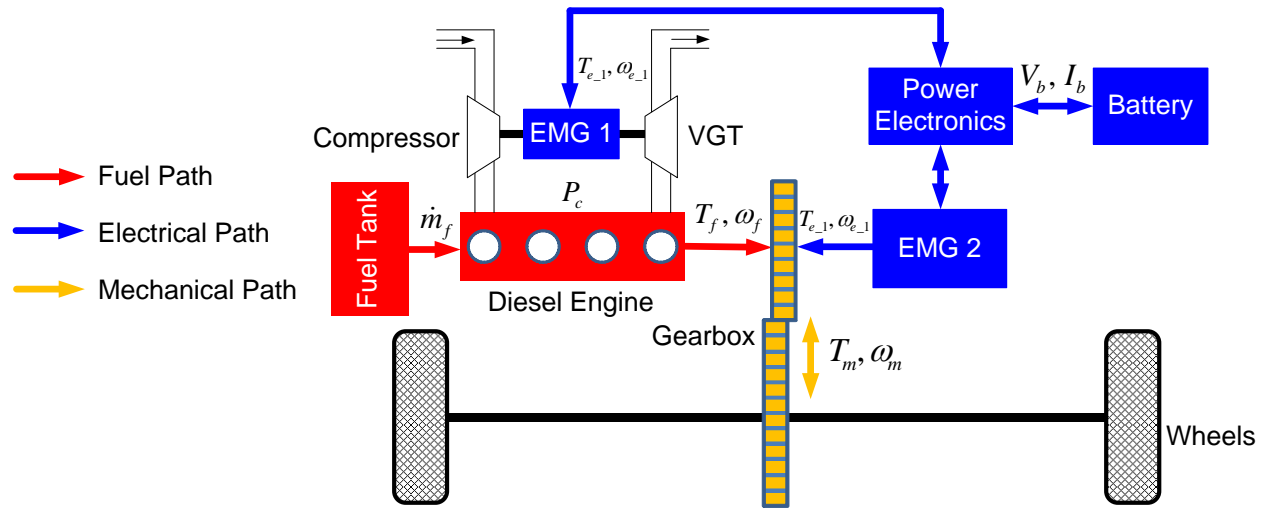

Fig. 1. Schematic of a diesel engine-equipped power-split HEV

\section{A. Fuel Path}

The operating conditions of the engine are determined by the engine speed and torque. The available generated power from the engine combustion is

$$
P_{a}(t)=H_{\mathrm{LHV}} \dot{m}_{f}(t),
$$

where $H_{\mathrm{LHV}}$ is the lower heating value of the fuel and $\dot{m}_{f}(t)$ is the fueling rate. Consequently, the energy consumed by the engine is

$$
E_{f}(t)=\int_{0}^{t} H_{\mathrm{LHV}} \dot{m}_{f}(\tau) \mathrm{d} \tau
$$

The transmitted power from the engine to the gearbox is calculated by

$$
P_{f}(t)=\eta_{a} P_{a}(t),
$$

where $\eta_{a}$ is the energy transmission efficiency from engine combustion to mechanical propulsion considering friction, pumping, and heat losses. Therefore, the available torque on the fuel path is

$$
T_{f}(t)=P_{f}(t) / \omega_{f}(t),
$$

where $\omega_{f}(t)$ is the rotating speed of the crankshaft linking the engine and the gearbox.

\section{B. Electrical Path}

The power electronics manages the electrical energy flows between the battery, EMG 1, and EMG 2. Modeling the battery as an equivalent circuit, the voltage of the battery is introduced as [2]

$$
V_{b}(t)=V_{\mathrm{oc}}\left(S O C, \lambda_{c}, T_{b}\right)-I_{b}(t) R_{b}\left(S O C, \lambda_{c}, T_{b}\right),
$$

where $V_{\text {oc }}\left(S O C, \lambda_{c}, T_{b}\right), I_{b}(t)$ and $R_{b}\left(S O C, \lambda_{c}, T_{b}\right)$ are the open circuit voltage, charging/discharging current, and internal resistance of the battery, respectively. $V_{\mathrm{oc}}\left(S O C, \lambda_{c}, T_{b}\right)$ and $R_{b}\left(S O C, \lambda_{c}, T_{b}\right)$ are functions of the battery $\mathrm{SOC}$, battery charging/discharging rate $\lambda_{c}$, and battery temperature $T_{b}$, respectively [50]. The functions can be extracted from the manufacturer's data [51]. The electrical power generated by the battery is

$$
P_{b}(t)=V_{b}(t) I_{b}(t)
$$

and accordingly, the consumed electrical energy of the battery is

$$
E_{e}(t)=\int_{0}^{t} V_{b}(\tau) I_{b}(\tau) \mathrm{d} \tau
$$

The battery SOC can be calculated by

$$
\operatorname{SOC}(t)=\operatorname{SOC}_{0}-\frac{1}{C_{b}} \int_{0}^{t} I_{b}(\tau) \mathrm{d} \tau,
$$

where $\mathrm{SOC}_{0}$ is the initial value of $\mathrm{SOC}$ and $C_{b}$ denotes the nominal capacity of the battery. In battery charging and discharging, $C_{b}$ changes slightly due to the variations in the battery internal temperature and current direction. The reader can refer to [52] for more details. The generated/consumed power of the electrical path is:

$$
P_{e}(t)=\sum_{i=1}^{2} P_{e_{i} i}(t),
$$

with $P_{e_{-} i}(t)=T_{e_{-} i}(t) \omega_{e_{-} i}(t)$, where $T_{e_{-} i}(t)$ and $\omega_{e_{-} i}(t)$ are the available torque and rotating speed of EMG $i$, respectively. Neglecting power losses, $P_{b}(t)=P_{e}(t)$. When $P_{b}(t)$ is positive, EMG 1 and EMG 2 work in the engine acceleration mode. When $P_{b}(t)$ is negative, EMG 1 and EMG 2 work in the energy harvesting mode.

\section{Mechanical Path}

The required power to drive the vehicle is calculated using a quasi-static model. At a given vehicle speed $v(t)$ and road slope $\alpha(t)$, the required force to drive the wheels is

$$
\begin{aligned}
F_{m}(t)= & m \dot{v}(t)+0.5 \rho C_{d} A_{d} v(t)^{2} \\
& +m g \sin (\alpha(t))+m g C_{r} \cos (\alpha(t)),
\end{aligned}
$$

where the four terms are vehicle acceleration force, aerodynamic drag force, resistive gravity force, and rolling resistance force, respectively; $m, g, \rho, C_{d}, A_{d}$, and $C_{r}$ are the vehicle mass, gravity constant, air density, air drag coefficient, frontal area, and rolling resistance, respectively. The wheel torque $T_{m}(t)$ and angular speed $\omega_{m}(t)$ are given by

$$
\begin{gathered}
T_{m}(t)=F_{m}(t) r_{w}, \\
\omega_{m}(t)=v(t) / r_{w},
\end{gathered}
$$


respectively, where $r_{w}$ is the radius of the wheels. The required power to drive the vehicle is

$$
P_{m}(t)=T_{m}(t) \omega_{m}(t)
$$

and therefore, the mechanical energy delivered to the wheels is

$$
E_{m}(t)=\int_{0}^{t} T_{m}(\tau) \omega_{m}(\tau) \mathrm{d} \tau .
$$

According to the power balance principle, $P_{m}(t)$ is always assumed to be fulfilled by the power delivered by the fuel path and electrical path:

$$
P_{m}(t)=P_{f}(t)+P_{e_{-} 2}(t),
$$

while the regulation of $P_{e_{-} 1}(t)$ on the turbine shaft impacts the available $P_{f}(t)$.

A parameter $\lambda_{d c_{-} i}$ is introduced to depict the working modes of EMG $i(i=\{1,2\})$ :

$$
\lambda_{d c_{-} i}=P_{\text {eff } \_i} / P_{\text {rated } \_} i,
$$

where $P_{\text {eff } \_i}$ and $P_{\text {rated } \_i}$ are the effective power and rated power of EMG $i$, respectively. EMG $i$ works at different modes owing to different $\lambda_{d c_{-} i}$ settings:

1) If $\lambda_{d c_{-} i}>0$, EMG $i$ works in the electric motor mode, while the energy is extracted from the battery to the crankshaft or the turbocharger shaft;

2) If $\lambda_{d c_{-} i}=0$, EMG $i$ is shut off;

3) If $\lambda_{d c_{-} i}<0$, EMG $i$ works in the generator mode, while the energy is generated from crankshaft or turbocharger shaft to the battery.

When $\lambda_{d c_{-} i}=-1$ is set, EMG $i$ works with the maximum regenerative power. When $\lambda_{d c_{-} i}=1$ is set, EMG $i$ works with the maximum assist power. In the proposed method, $\lambda_{d c_{-} 1}=$ $\lambda_{d c_{-} 2}$ is set, which means EMG 1, EMG 2, battery, and power electronics work together as an electric turbo compounding system. Therefore, $\lambda_{d c_{-} 1}$ and $\lambda_{d c_{-} 2}$ are lumped together as $\lambda_{d c}$. To describe the power distribution in parallel paths, a variable $\beta(t)$ is employed:

$$
\beta(t)=P_{e_{-} 2}(t) / P_{m}(t) .
$$

The HEV operates at different modes with different $\beta(t)$ values:

1) If $\beta(t)=1$, the HEV works in the motor driven mode, while $\lambda_{d c_{-} 2}>0$ is held. The propulsion power is provided by EMG 2, i.e., $P_{m}(t)=P_{e_{-} 2}(t)$. The battery is discharging;

2) If $0<\beta(t)<1$, the HEV works in the hybrid mode, while $\lambda_{d c_{-} 2}>0$ is held. The propulsion power is provided by both the engine and EMG 2. The battery is discharging;

3) If $\beta(t)=0$, the HEV works in the non-hybrid mode, while $\lambda_{d c_{-} 2}=0$ is held. The propulsion power is provided by the engine alone, i.e., $P_{m}(t)=P_{f}(t)$;

4) If $\beta(t)<0$, the HEV works in the regenerative mode, while $\lambda_{d c_{-} 2}<0$ is held. The propulsion power is provided by the engine. The battery is charging and EMG 2 works as a generator.

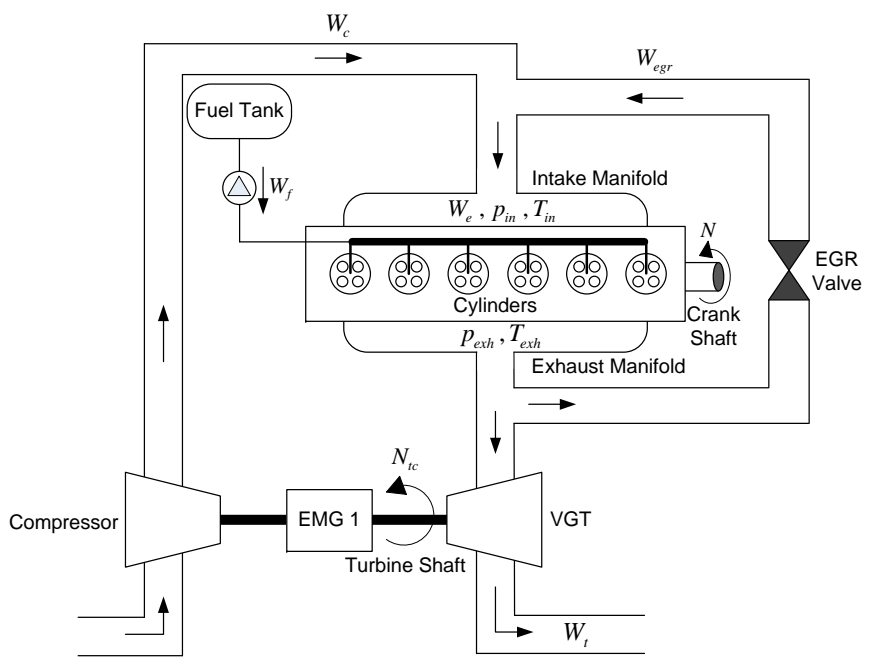

Fig. 2. Schematic of the electric turbocharged diesel engine

TABLE I

NOMENCLATURE

\begin{tabular}{ll}
\hline Variable & Description \\
\hline$N$ & Engine speed \\
$W_{f}$ & Engine fuelling rate \\
$W_{c}$ & Compressor air mass flow rate \\
$W_{e g r}$ & EGR mass flow rate \\
$W_{e}$ & Engine total mass flow rate \\
$W_{t}$ & Turbine gas mass flow rate \\
$P_{c}$ & Compressor power \\
$P_{t}$ & Turbine power \\
$p_{i n}$ & Intake manifold pressure \\
$p_{e x h}$ & Exhaust manifold pressure \\
$p_{a m}$ & Ambient pressure \\
$T_{i n}$ & Intake manifold temperature \\
$T_{e x h}$ & Exhaust manifold temperature \\
$N_{t c}$ & Turbocharger speed \\
$F_{1}$ & Burnt gas fraction \\
$\lambda_{a}$ & Air-fuel ratio \\
$R$ & Specific gas constant \\
$\tau$ & Turbocharger time constant \\
$\eta_{c}$ & Compressor isentropic efficiency \\
$\eta_{t}$ & Turbine isentropic efficiency \\
$\eta_{m}$ & Turbocharger mechanical efficiency \\
$\chi_{e g r}$ & EGR valve position \\
$\chi_{v g t}$ & VGT vane position \\
$c_{p}$ & Specific heat at constant pressure \\
$\gamma$ & Specific heat ratio \\
$\mu$ & q-1 \\
\hline
\end{tabular}

It is expected that the decision of the energy management, that is the on-line output $\beta(t)$ of the supervision controller leads to the optimal fuel economy while fulfilling the driving command and maintaining the battery SOC within an allowed range.

\section{Diesel Engine Air Path}

The schematic of a conventional turbocharged diesel engine is shown in Fig. 2, where its variables and related parameters are defined in Table I. The VGT converts exhaust gas energy to mechanical energy by using the work output from the exhaust gas turbine to operate the compressor. The compressor increases the density of the fresh air supplied to the engine which in turns results in higher torque. The EGR path directs exhaust gas back to the inlet manifold to dilute the air, 
resulting in lower oxygen concentration, increased charge heat capacity, and consequently lower combustion temperature, and therefore lower $\mathrm{NO}_{\mathrm{x}}$ emissions. The fuel is injected directly to the engine cylinders and burnt with expanding combustion products, producing the torque at the crankshaft.

The exhaust performance variables of the diesel engine are defined as $\mathrm{NO}_{x}$ and $\mathrm{PM}$, while their reduction is achieved by keeping a sufficient large value of $F_{1}$ and $\lambda_{a}$ in the intake manifold, respectively. Therefore, $F_{1}$ and $\lambda_{a}$ are employed as the engine performance variables, defined by

$$
F_{1}=\frac{W_{e g r}}{W_{c}+W_{e g r}} \quad \lambda_{a}=\frac{W_{c}}{W_{f}} .
$$

Precise tracking of $F_{1}$ and $\lambda_{a}$ to their optimal setpoint values $F_{1}^{*}$ and $\lambda_{a}^{*}$ is desired. $W_{c}$ and $p_{i n}$ are measured to provide the information about the intake gas process and are closed-loop controlled by the VGT vane and EGR valve. VGT and EGR actuators are strongly coupled because they both interact with the exhaust gas flow.

EMG 1 mounted on the turbocharger shaft can work in both assist mode and generator mode. In assist mode, EMG 1 accelerates the turbocharger during transients to improve engine response, or provides steady state boost pressure to enhance low speed torque. In generator mode, excess turbine power is recovered by generating electricity and stored in a battery. EMG 1 is functioning in both fuel economy optimization and transient response acceleration. When transient response acceleration is the target, the effectiveness of EMG 1 in improving transient performance is demonstrated in Fig. 3, where the engine runs at a speed of $1600 \mathrm{rpm}$, the load changes from $100 \mathrm{Nm}$ to $900 \mathrm{Nm}$ during [5s, 6s], and the power of EMG 1 is set to different values during [5s, 10s]. EMG 2 was shut off in these engine transient response acceleration tests.

The dynamic model of the engine air path is derived based on the conservation of mass and energy and the ideal gas law. Ignoring the slow deviation of $T_{i n}$ and $T_{e x h}$ and considering the impact of EMG 1 on the engine air path dynamics, a thirdorder nonlinear control-oriented mean value air path model is formulated with respect to $p_{i n}, p_{e x h}$, and $P_{c}$ [53]:

$$
\begin{aligned}
\dot{p}_{i n} & =\frac{R T_{\text {in }}}{V_{\text {in }}}\left(W_{c}+W_{e g r}-W_{e}\right), \\
\dot{p}_{e x h} & =\frac{R T_{e x h}}{V_{\text {exh }}}\left(W_{e}-W_{e g r}-W_{t}+W_{f}\right), \\
\dot{P}_{c} & =\frac{1}{\tau}\left(\eta_{m} P_{t}+P_{e_{-} 1}-P_{c}\right) .
\end{aligned}
$$

$W_{c}$ is related to $P_{c}$ by

$$
W_{c}=\frac{\eta_{c}}{c_{p} T_{a}} \frac{P_{c}}{p_{i n}^{\mu}-1},
$$

while $P_{t}$ can be expressed by $W_{t}$ :

$$
P_{t}=\eta_{t} c_{p} T_{e x h}\left(1-p_{e x h}^{-\mu}\right) W_{t} .
$$

The mass flow rate through the EGR valve can be obtained

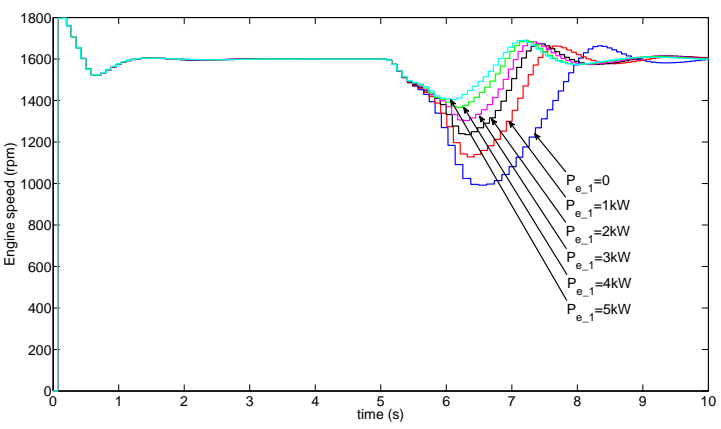

(a) Engine speed response

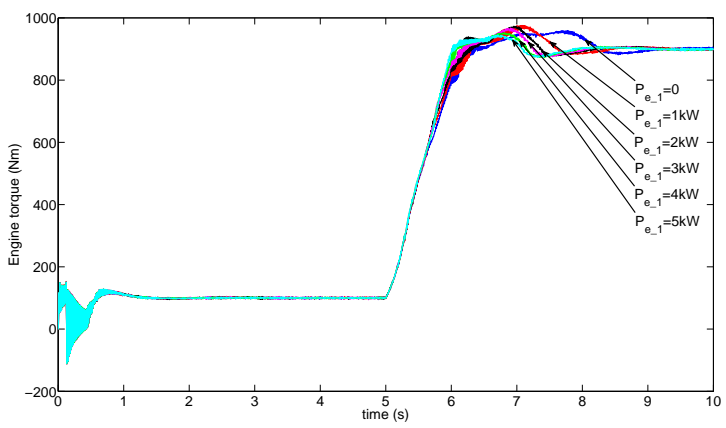

(b) Engine torque response

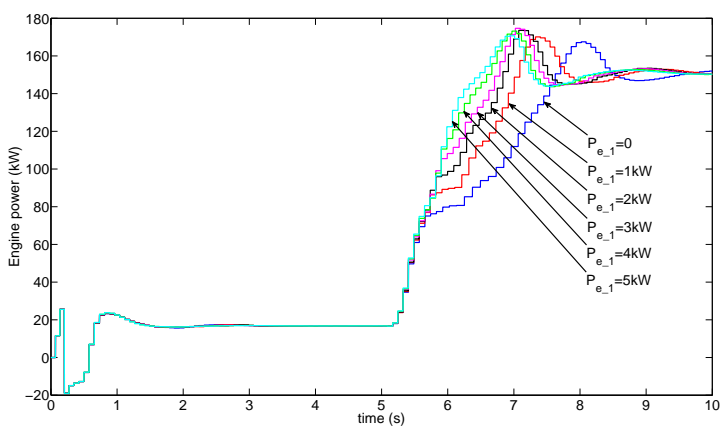

(c) Engine power response

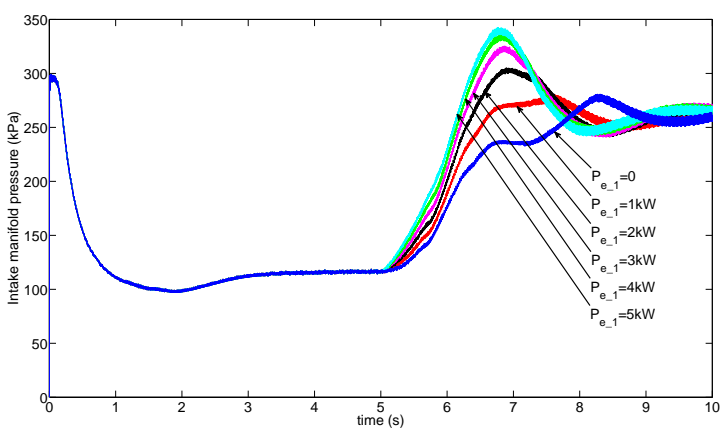

(d) Boost pressure response

Fig. 3. The effectiveness of EMG 1 in accelerating engine transient response

by the actuator map given by:

$$
W_{\text {egr }}=\left\{\begin{aligned}
A_{\text {egr }}\left(\chi_{\text {egr }}\right) \frac{p_{\text {exh }}}{\sqrt{R T_{\text {exh }}}} \Psi\left(\frac{p_{\text {in }}}{p_{\text {exh }}}\right), & \text { if } p_{\text {in }}<p_{\text {exh }} ; \\
0, & \text { if } p_{\text {in }}=p_{\text {exh }} ; \\
A_{\text {egr }}\left(\chi_{\text {egr }}\right) \frac{p_{\text {in }}}{\sqrt{R T_{\text {in }}}} \Psi\left(\frac{p_{\text {exh }}}{p_{\text {in }}}\right), & \text { if } p_{\text {exh }}<p_{\text {in }} ;
\end{aligned}\right.
$$




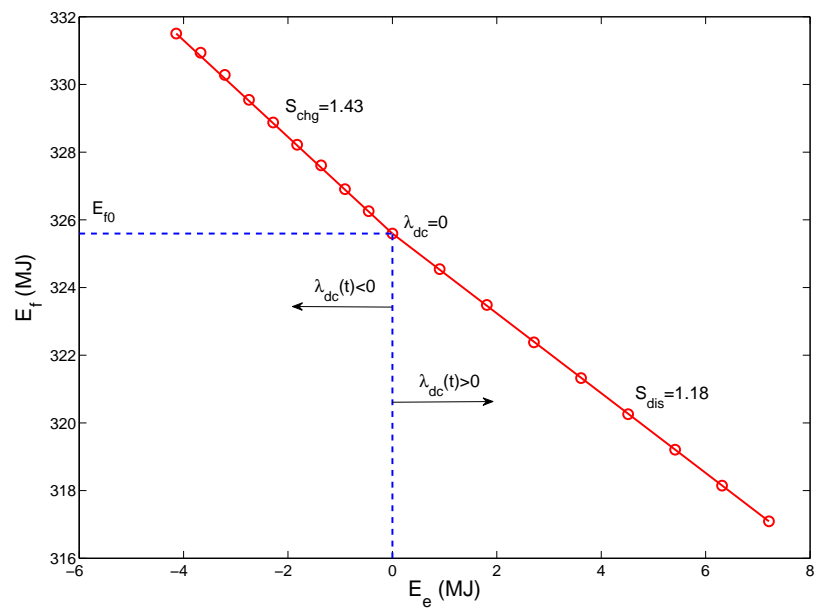

Fig. 4. Equivalent factors $s_{\text {chg }}$ and $s_{\text {dis }}$ under NRTC, $1200 \mathrm{~s}$

where

$$
\Psi\left(\frac{p_{i}}{p_{j}}\right)=\left\{\begin{array}{c}
\gamma^{0.5}\left(\frac{2}{\gamma+1}\right)^{(\gamma+1) /(2(\gamma-1))}, \\
\text { if } \frac{p_{i}}{p_{j}} \leq\left(\frac{2}{\gamma+1}\right)^{\gamma /(\gamma-1)}
\end{array} ;\right.
$$

and $A_{e g r}$ is the EGR effective flow with a quadratic function with respect to $\chi_{\text {egr }}$. The turbine mass flow rate is represented by a modified version of the orifice equation:

$$
W_{t}=A_{v g t}\left(\chi_{v g t}\right) \frac{p_{e x h}}{\sqrt{R_{g} T_{e x h}}} \Phi\left(\frac{p_{a m}}{p_{e x h}}, \chi_{v g t}\right)
$$

where $A_{v g t}$ is a quadratic function with respect to $\chi_{v g t}$ and $\Phi\left(\frac{p_{a m}}{p_{\text {exh }}}, \chi_{v g t}\right)$ is obtained from a VGT mass flow rate map. The reader can refer to [43] for further details on the air path dynamics.

\section{PROBLEM Formulation}

The target of the real-time energy management strategy is to maximize the fuel economy of a HEV. The optimization problem can be explicitly formulated as minimizing the following cost function in terms of energy:

$J_{f}\left(t_{f}, u, \mathrm{SOC}\right)=\int_{t_{0}}^{t_{f}} \dot{m}_{f}(\tau, u, x) \mathrm{d} \tau+\varphi\left(\operatorname{SOC}\left(t_{0}\right), \operatorname{SOC}\left(t_{f}\right)\right)$,

subject to the HEV powertrain dynamic equations and the physical constraints including the allowed operation ranges on the battery SOC, motors speed, motors torque, and actuators position. In (25), $u$ denotes the control variables; $x$ denotes the engine, motor and battery states; $\operatorname{SOC}\left(t_{0}\right)$ and $\operatorname{SOC}\left(t_{f}\right)$ are initial SOC value and final SOC value, respectively; and $\varphi(\cdot)$ is the penalty function regarding the SOC deviation from its initial value to the final value. The penalty function is also called the equivalent fuel consumption. For the sake of optimality, the boundary condition of the terminal state

$$
\operatorname{SOC}\left(t_{0}\right)=\operatorname{SOC}\left(t_{f}\right)
$$

is to be satisfied [11].

\section{A. Instantaneous Cost Function}

In the ideal case, the optimal power ratio to minimize the cost function (25) can be obtained by applying the Pontryagin's minimum principle [54]. It is difficult to find analytical solutions in general, due to nonlinearities and dependence on future driving conditions and power demands. In the ECMS, the cost function is defined in terms of the instantaneous power:

$$
J(t, u, \mathrm{SOC})=P_{a}(t, u, x)+s(t, \mathrm{SOC}) P_{b}(t, u, x),
$$

where $s(t, \mathrm{SOC})$ is a non-dimensional fuel energy equivalent factor. The ECMS transfers the global optimization problem to minimization of an instantaneous equivalent power at each instant [40]. Therefore, the on-line optimization problem is formulated as

$$
\begin{array}{ll}
\text { Minimize : } & J(t, u, \mathrm{SOC}), \quad \forall t \in\left[t_{0}, t_{f}\right] \\
\text { Subject to : } & x_{\min } \leq x \leq x_{\max }, \\
& u_{\min } \leq u \leq u_{\max } .
\end{array}
$$

The key issue in implementing the ECMS is on-line evaluation of $s(t, \mathrm{SOC})$, which varies with the battery SOC. As a prior knowledge, $s(t, \mathrm{SOC})$ can be expressed as a function of equivalent factors $s_{\mathrm{chg}}$ and $s_{\mathrm{dis}}$, which reveal the equivalent conversion ratio between the fuel chemical energy and the electrical energy in battery charging and discharging, respectively. For a specified diesel engine running under certain operating conditions, $s_{\mathrm{chg}}$ and $s_{\mathrm{dis}}$ are determined physical constants. By setting incremental $\lambda_{d c}(t)$ in repeated tests, the consumed energy map can be plotted on a coordinated plane with respect to $E_{e}\left(t_{f}\right)$ and $E_{f}\left(t_{f}\right)$. The terms $s_{\text {chg }}$ and $s_{\text {dis }}$ are the slopes of the fitted straight lines over the obtained points. As an example, $s_{\text {chg }}$ and $s_{\text {dis }}$ of the $\mathrm{CAT}^{\circledR} \mathrm{C} 15$ heavy duty diesel engine under the non-road transient cycle (NRTC) are illustrated in Fig. 4. In the repeated tests, only $\lambda_{d c}$ is tuned, while the other actuators remain as constant values.

The diesel HEV works in the non-hybrid mode when $\lambda_{d c}(t)=0$ is applied, and the corresponding fuel energy consumption is indicated as $E_{f 0}$. The fuel consumption in the other working modes can be calculated by

$$
E_{f}\left(t_{f}\right)=\left\{\begin{array}{r}
E_{f 0}-s_{\mathrm{dis}} E_{e}\left(t_{f}\right), \\
\text { if } \lambda_{d c}(t)>0 \quad \forall t \in\left[t_{0}, t_{f}\right] \\
E_{f 0}-s_{\operatorname{chg}} E_{e}\left(t_{f}\right), \\
\text { if } \lambda_{d c}(t)<0 \quad \forall t \in\left[t_{0}, t_{f}\right]
\end{array}\right.
$$

where $E_{e}\left(t_{f}\right)>0$ when $\lambda_{d c}(t)>0$, and $E_{e}\left(t_{f}\right)<0$ when $\lambda_{d c}(t)<0$.

The cost factor $s(t, \mathrm{SOC})$ need to be designed as a decreasing function with respect to $\operatorname{SOC}(t)$, and its changing trend is shown in Fig. 5. At the beginning, $s\left(t_{0}, \mathrm{SOC}\left(t_{0}\right)\right)=s\left(t_{0}\right)$. When the battery is discharging, i.e., $\operatorname{SOC}(t)<\operatorname{SOC}\left(t_{0}\right)$, then $s(t, \mathrm{SOC})>s\left(t_{0}\right)$ is held, the consumption of electrical 


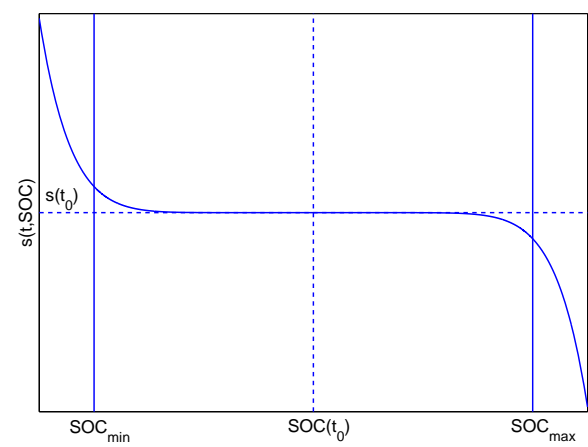

Fig. 5. Changing trend of the cost factor $s(t, \mathrm{SOC})$

energy has a higher penalty and results in the discharging trend being suppressed. On the other hand, when the battery is charging and $s(t, \mathrm{SOC})$ is greater than $s\left(t_{0}\right)$, further charging is discouraged by $s(t, \mathrm{SOC})$ falling below $s\left(t_{0}\right)$. If $\mathrm{SOC}$ exceeds its permitted region $\left[\mathrm{SOC}_{\min }, \mathrm{SOC}_{\max }\right], s(t, \mathrm{SOC})$ changes dramatically, hence the deviation of the current SOC from $\operatorname{SOC}\left(t_{0}\right)$ is remedied in a short time.

\section{B. Control Variables and Constraints}

Besides the $\lambda_{d c}(t)$ on the powertrain side, the AFR $\lambda_{a}$ is also an important factor in impacting the engine fuel economy and exhaust emissions, and is regulated by the VGT and EGR actuators. Therefore, in the proposed method, the control variables are defined as the vector:

$$
u(t)=\left\{\lambda_{d c}(t), \chi_{e g r}(t), \chi_{v g t}(t)\right\} .
$$

For VGT and EGR actuators are primarily used to regulate exhaust emissions, the tuning of which should comply with exhaust emission standards. Due to the fast transient dynamics of off-highway vehicles in applications, the physical constraints on $\chi_{e g r}$ and $\chi_{v g t}$ vary under different operating conditions, to meet the exhaust emission standards. The restrictions on the control variables are formulated as:

$$
\left\{\begin{array}{l}
\lambda_{d c_{\_} \min } \leq \lambda_{d c}(t) \leq \lambda_{d c \_\max } \\
\chi_{\text {egr_min }} \leq \chi_{\text {egr }}(t) \leq \chi_{\text {egr_max }}, \\
\chi_{v g t_{-} \min } \leq \chi_{v g t}(t) \leq \chi_{v g t \_\max },
\end{array}\right.
$$

Furthermore, the operating range of the HEV components is limited, so physical constraints have to be set on the speed and torque of electric motors and the battery SOC:

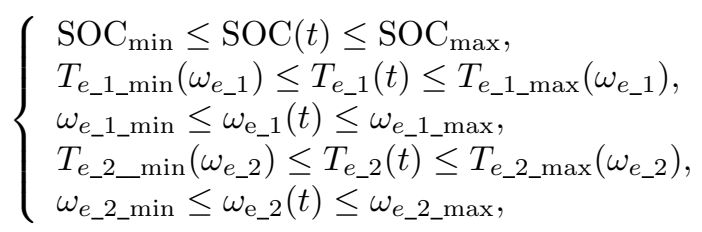

where the torque limits of the electric motors depend on the engine speed. The inequalities (31), (32) and equation (26) constitute the constraints set in the problem formulation (28).

\section{Real-Time Optimal Energy Management STRATEGY}

The proposed real-time optimal energy management strategy is denoted as F-ECMS, and its application to a diesel

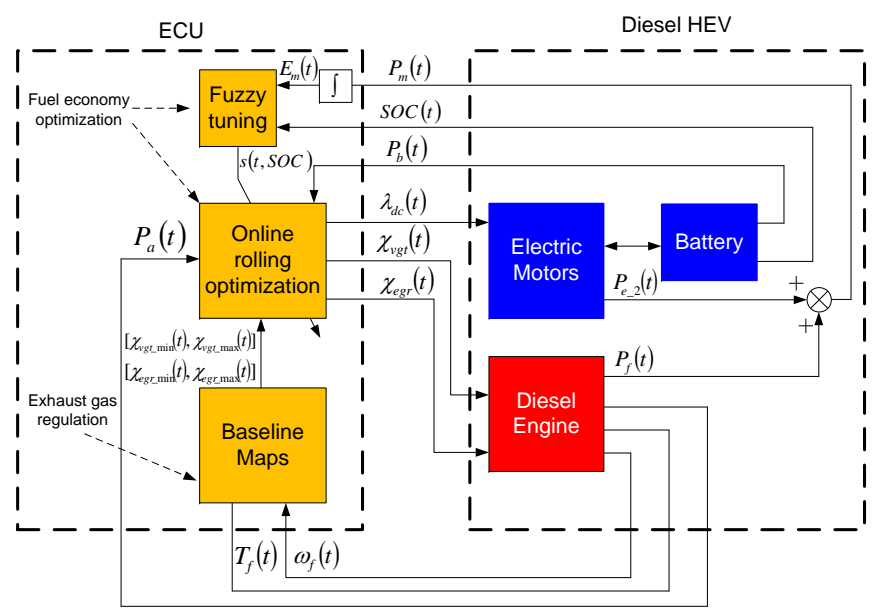

Fig. 6. Application of F-ECMS on a diesel engine-equipped heavy duty HEV

engine-equipped off-highway HEV is illustrated in Fig. 6. The outputs of the energy management module are $\lambda_{d c}(t)$, $\chi_{v g t}(t)$, and $\chi_{e g r}(t)$, which are the control variables of the on-board motors diesel engine. They are updated according to the instantaneous cost function, which is calculated by the feedback variables $P_{a}(t), P_{b}(t)$, and the cost factor $s(t, \mathrm{SOC})$.

\section{A. Cost Factor Fuzzy Tuning}

The cost factor $s(t, \mathrm{SOC})$ is the most important parameter to be designed in a real-time energy management scheme. In the proposed method, $s(t, \mathrm{SOC})$ is constructed as a probability model

$$
s(t, \mathrm{SOC})=s\left(t_{0}\right) p(t),
$$

where $p(t)$ is used to reflect the deviation of $\operatorname{SOC}(t)$ and its effect on the fuel economy. The initial value of $s(t, \mathrm{SOC})$ is defined as

$$
s\left(t_{0}\right)=\sqrt{s_{\mathrm{chg}} s_{\text {dis }}} .
$$

A key strength of fuzzy control is powerful in capturing the imprecision of reasoning processes without using exact quantitative analysis. Compared with analytical tools, a fuzzy system is more tolerant of system model accuracy. The fuzzy logic is introduced to evaluate $p(t)$ on-line to deal with the system nonlinearities, numerous constraints defined in (26), (31) and (32), and the un-modeled dynamics.

The probability $p(t)$ is determined depending on the $\mathrm{SOC}(t)$ and $E_{m}(t) / E_{m}\left(t_{f}\right)$, which are used to evaluate the deviation of battery SOC and the task progress in the test cycles.

TABLE II

FUZZY RULES FOR $p(t)$ TUNING

\begin{tabular}{|c|c||c|c|c|c|c|c|c|}
\hline \multicolumn{2}{|c||}{$p(t)$} & \multicolumn{7}{|c|}{$\mathrm{SOC}(t)$} \\
\cline { 3 - 9 } & & NB & NM & NS & ZO & PS & PM & PB \\
\hline \hline \multirow{3}{*}{$\frac{E_{m}(t)}{E_{m}\left(t t_{f}\right)}$} & ZO & ZO & ZO & ZO & ZO & ZO & ZO & ZO \\
\cline { 2 - 8 } & PS & ZO & ZO & ZO & ZO & ZO & ZO & ZO \\
\cline { 2 - 9 } & PM & ZO & ZO & ZO & ZO & ZO & ZO & ZO \\
\cline { 2 - 9 } & PB & PB & PM & PS & ZO & NS & NM & NB \\
\hline
\end{tabular}



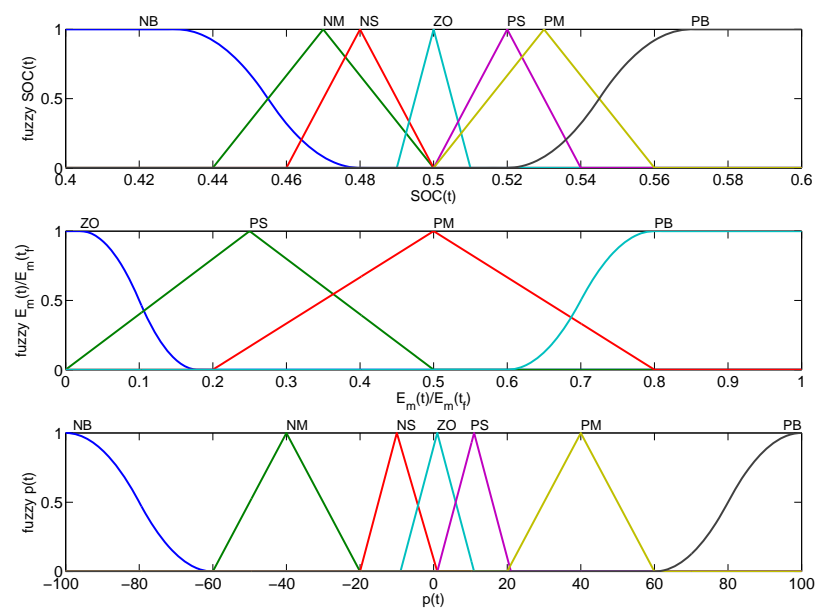

Fig. 7. Membership functions of the $p(t)$ tuning related variables

1) Cost factor tuning within $\left[\mathrm{SOC}_{\min }, \mathrm{SOC}_{\max }\right]$ : When $\mathrm{SOC}(t) \in\left[\mathrm{SOC}_{\min }, \mathrm{SOC}_{\max }\right]$ is satisfied, the fuzzy rules for $p(t)$ tuning is shown as Table II, and the membership functions are defined as Fig. 7. The main points are summarized as

(i) In the early stage and middle stage of the test cycles (e.g. $E_{m}(t) / E_{m}\left(t_{f}\right)<0.6$ in NRTC), fuzzy tuning is noneffective, which means $p(t)$ is calculated according to the principle of minimizing the cost function $J(t, u, \mathrm{SOC})$, without regarding the status of battery SOC.

(ii) In the late stage of the test cycles (e.g. $E_{m}(t) / E_{m}\left(t_{f}\right) \geq$ 0.6 in NRTC), the deviation of battery SOC is accounted in $p(t)$ tuning, such that $\mathrm{SOC}(t)$ is driven to the demand value at the end of the test cycles. The fuzzy tuning rules are listed in more details as following:

- If the $\operatorname{SOC}(t)$ is too low (negative big, NB in short), charge the battery as much as possible.

- If the $\operatorname{SOC}(t)$ is relatively low (negative medium, NM in short), charge the battery at a rather quick rate.

- If the $\operatorname{SOC}(t)$ is a little low (negative small, NS in short), charge the battery at a rather slow rate.

- If the $\operatorname{SOC}(t)$ is around its demand value (zero, ZO in short), do not charge or discharge the battery.

- If the $\operatorname{SOC}(t)$ is a little high (positive small, PS in short), discharge the battery at a rather slow rate.

- If the $\operatorname{SOC}(t)$ is relatively high (positive medium, PM in short), discharge the battery at a rather quick rate.

- If the $\mathrm{SOC}(t)$ is too high (positive big, $\mathrm{PB}$ in short), discharge the battery as much as possible.

2) Cost factor tuning without $\left[\mathrm{SOC}_{\min }, \mathrm{SOC}_{\max }\right]$ : If the $\operatorname{SOC}(t)$ exceeds its allowed operation range, $p(t)$ is defined as an exponential function to rapidly restrain the changing trend of $\operatorname{SOC}(t)$ :

$$
p(t)=\left\{\begin{array}{c}
\exp \left(\frac{\mathrm{SOC}(t)-\mathrm{SOC}\left(t_{0}\right)}{\mathrm{SOC}(t)-\mathrm{SOC} \text { min }}\right) \\
\text { if } \mathrm{SOC}(t)<\mathrm{SOC}_{\min } \\
\exp \left(\frac{\mathrm{SOC}(t)-\mathrm{SOC}\left(t_{0}\right)}{\mathrm{SOC} \max -\mathrm{SOC}(t)}\right), \\
\text { if } \operatorname{SOC}(t)>\mathrm{SOC}_{\max }
\end{array} .\right.
$$

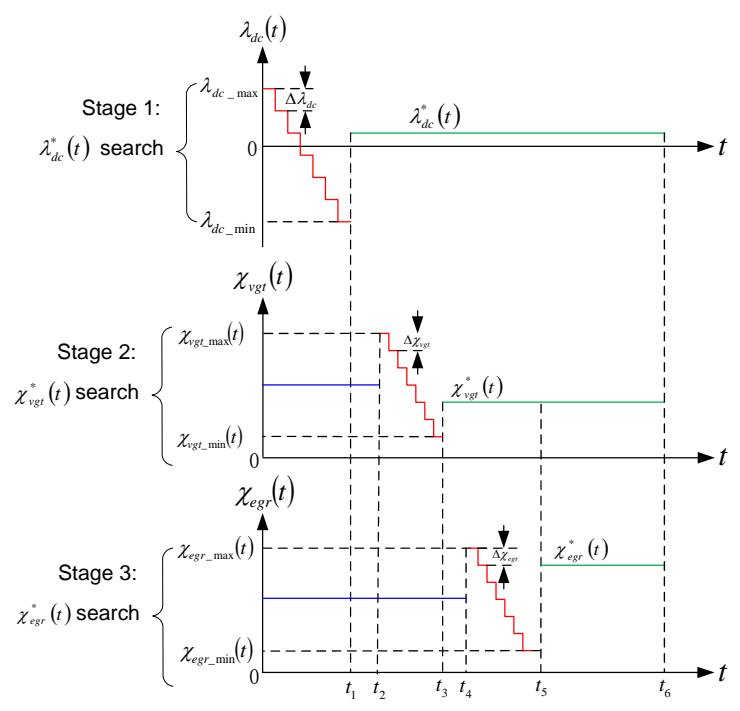

Fig. 8. On-line search of the optimal setpoints

\section{B. On-line rolling Optimization}

An on-line rolling optimization method is employed to find the optimal setpoints of the three variables, whose demonstration in a cycle is illustrated in Fig. 8. The parameter $\lambda_{d c}(t)$ is the primary variable to be optimized, which plays a key role in optimizing fuel economy. The searching process of $\lambda_{d c}^{*}(t)$ is shown as stage 1 . During the time horizon $\left[0, t_{1}\right], \lambda_{d c}(t)$ reduces with the step of $\Delta \lambda_{d c}$ at each sampling period in the allowed range $\left[\lambda_{d c_{-} \text {min }}, \lambda_{d c_{-} \text {max }}\right]$, and the found optimal power ratio $\lambda_{d c}^{*}(t)$ is executed during the time horizon $\left[t_{1}, t_{6}\right]$.

The searching process of $\chi_{v g t}^{*}(t)$ and $\chi_{\text {egr }}^{*}(t)$ are shown as stage 2 and stage 3 , respectively. In stage 2 , during the time horizon $\left[0, t_{2}\right], \chi_{v g t}(t)$ is controlled in closed-loop, where the time horizon $\left[t_{1}, t_{2}\right]$ is employed for engine stabilization. During the time horizon $\left[t_{2}, t_{3}\right], \chi_{v g t}(t)$ is optimized with the steps of $\Delta \chi_{v g t}$ in a ECU embedded simulation model. Meanwhile, the actual $\chi_{v g t}(t)$ applied on the engine is kept as $\chi_{v g t}\left(t_{2}\right)$. During the time horizon $\left[t_{3}, t_{6}\right]$, the new optimal VGT position $\chi_{v g t}^{*}(t)$ is applied. Similarly, in stage 3 , during the time horizon $\left[0, t_{4}\right], \chi_{\text {egr }}(t)$ is controlled in closed-loop, where the time horizon $\left[t_{3}, t_{4}\right]$ is employed for engine stabilization. During the time horizon $\left[t_{4}, t_{5}\right], \chi_{\text {egr }}(t)$ is optimized with the steps of $\Delta \chi_{e g r}$ in the ECU embedded simulation model. Meanwhile, the actual $\chi_{\text {egr }}(t)$ applied to the engine is kept as $\chi_{\text {egr }}\left(t_{4}\right)$. During the time horizon $\left[t_{5}, t_{6}\right]$, the new optimal EGR position $\chi_{\text {egr }}^{*}(t)$ is applied. In this work, the online rolling optimization was implemented by a self-defined Matlab s-function.

For VGT and EGR actuators are primarily used to regulate exhaust emissions, the tuning of which should comply with exhaust emission standards. Due to the fast transient dynamics of off-highway vehicles, the physical constraints on $\chi_{v g t}(t)$ and $\chi_{\text {egr }}(t)$ vary under different operating conditions, to meet the exhaust emission standards. In the proposed method, the engine operation region is divided into several sub-zones according to different engine speed and load torque. In each subzone, the $\mathrm{NO}_{x}$ map and PM map are obtained via calibration. 


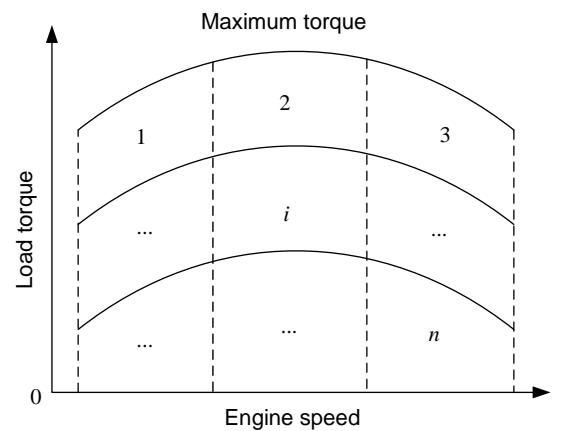

Fig. 9. Segmentation of the diesel engine operation region

The physical limits of $\chi_{v g t}(t)$ and $\chi_{e g r}(t)$ are generated regarding the exhaust emission maps. The number of subzones depends on the requirement on the model accuracy. As an illustration of Fig. 9, the engine operation region is segmented into $n$ sub-zones. In the sub-zone $i$, the restrictions of the actuator positions are

$$
\begin{aligned}
& \chi_{v g t}(t) \in\left[\chi_{v g t_{-} i_{-} \min } \chi_{v g t_{-} i_{-} \max }\right],
\end{aligned}
$$

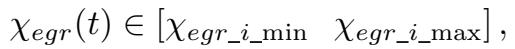

where the corner limits $\chi_{v g t \_i \_m i n}, \chi_{v g t \_i \_m a x}, \chi_{e g r \_i \_m i n}$, and $\chi_{\text {egr_i_max }}$ are identified in the off-line DOE tests. The corner limits are determined by the mechanical limits and engine emission limits, where the mechanical limits include the peak cylinder pressure limit, turbo speed limit, turbine inlet temperature limit, turbine inlet pressure limit, manifold delta pressure limit, min/max EGR opening, and $\min / \max$ VGT opening; the engine emission limits include the $\mathrm{NO}_{x}$ limit, AFR limit and smoke limit. As a demonstration, the allowable limits of VGT and EGR actuators at a fixed engine operating point and increasing $\lambda_{d c}$ are illustrated in Fig. 10.

\section{VALIDATION RESULTS}

The capability of the proposed F-ECMS in battery charge sustainability maintenance and fuel economy optimization is validated in this section. The simulation is conducted in the MATLAB/SIMULINK environment, with the fixed step of $0.01 \mathrm{~s}$. A CAT ${ }^{\circledR} \mathrm{C} 15$ heavy duty diesel engine equipped with

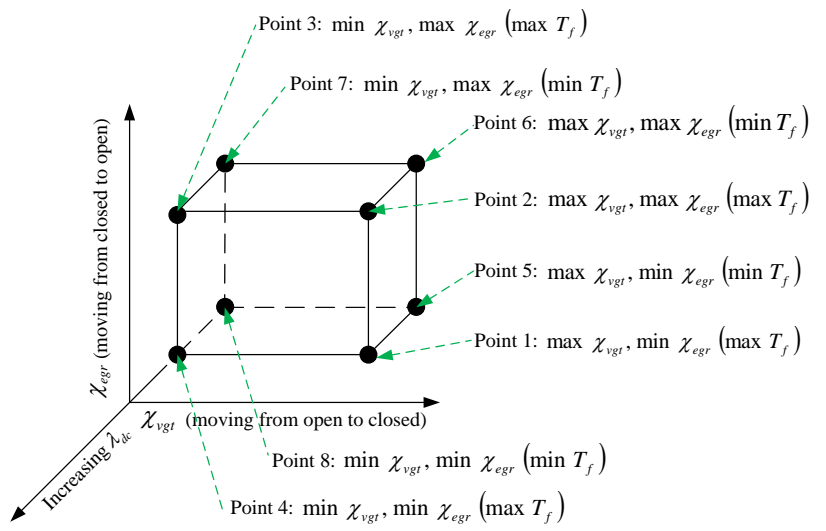

Fig. 10. Demonstration of the DOE test
TABLE III

Parameters of the Diesel HEV

\begin{tabular}{lll}
\hline \hline \multirow{3}{*}{ Diesel Engine } & Type & $15.2 \mathrm{~L}, 6$ inline cylinders \\
\cline { 2 - 3 } & Maximum Power & $460 \mathrm{~kW} @ 2100 \mathrm{rpm}$ \\
\cline { 2 - 3 } & Maximum Torque & $2780 \mathrm{Nm} @ 1200 \mathrm{rpm}$ \\
\hline \multirow{3}{*}{ EMG 1 } & Type & AC aysnchronous \\
\cline { 2 - 3 } & Maximum Power & $5 \mathrm{~kW}$ \\
\cline { 2 - 3 } EMG & Maximum Torque & $10 \mathrm{Nm}$ \\
\hline \multirow{3}{*}{ Type } & AC aysnchronous \\
\cline { 2 - 3 } & Maximum Power & $30 \mathrm{~kW}$ \\
\cline { 2 - 3 } & Maximum Torque & $500 \mathrm{Nm}$ \\
\hline & Type & Nickel-Metal-Hydride (NiMH), \\
& & 80 modules, each module con- \\
& sists 6 cells $1.2 \mathrm{~V}$ \\
\cline { 2 - 3 } & Nominal Voltage & $576 \mathrm{~V}$ \\
\cline { 2 - 3 } & Maximum Current & $200 \mathrm{~A}$ \\
\cline { 2 - 3 } & Capacity & $6.5 \mathrm{Ah}$ \\
\cline { 2 - 3 } & Maximum Power & $115 \mathrm{~kW}$ \\
\hline \hline
\end{tabular}

EMG 1 and EMG 2 installed on a chassis is used as the test platform, whose model has been experimentally validated over steady-state operating points. The parameters of the diesel engine, EMG 1, EMG 2, and battery are listed in Table III. The time horizons in Fig. 8 are set as $\left[0, t_{1}\right]=2.5 \mathrm{~s},\left[t_{1}, t_{4}\right]=2.5 \mathrm{~s}$. The other horizons vary with different upper and lower limits of VGT and EGR actuators at different sub-zones.

The NRTC and the hydraulic excavation transient cycle (HETC) are selected as test cycles, which are typical test cycles for off-highway heavy duty diesel engines. The HETC is a typical trenching cycle that the speed is maintained around the fixed value. The obtained equivalent cost factors $s_{\mathrm{chg}}, s_{\mathrm{dis}}$ for the NRTC and the HETC are listed in Table IV. The engine speed and load torque of the NRTC and the HETC are plotted in Fig. 11(a) and Fig. 11(b), respectively and these illustrate how the engine speed and torque change rapidly.

The battery capacity is a key parameter in affecting the fuel economy, which determines the limits of $\lambda_{d c}(t)$. Looking through the whole test cycle, the battery behaves as a buffer for energy storage. The global limits of $\chi_{v g t}(t)$ and $\chi_{e g r}(t)$ are determined according to the risk assessment. The parameters of the F-ECMS controller which are described in (31) and (32) are given in Table V. The ECMS can adjust the proportion between the fuel path and the electrical path within a rational range, such that the fuel power and the electrical power are distributed properly while satisfying the mechanical power constraint (15). The upper and lower limits placed on $\lambda_{d c}(t)$ are empirical values, due to the winding temperature of electric motors will increasing rapidly at high motor power.

The comparisons of the F-ECMS and the T-ECMS on battery SOC maintenance are shown in Fig. 12(a) and Fig. 12(b) respectively, where the T-ECMS has been commonly used in HEV energy management [29]. In the T-ECMS method, the

TABLE IV

PARAMETERs OF Test CyCles

\begin{tabular}{lll}
\hline \hline & NRTC & HETC \\
$s_{\text {chg }}$ & 1.43 & 1.42 \\
$s_{\text {dis }}$ & 1.18 & 1.23 \\
$E_{m}\left(t_{f}\right)$ & $132.3 \mathrm{MJ}$ & $59.5 \mathrm{MJ}$ \\
simulation time & $1200 \mathrm{~s}$ & $570 \mathrm{~s}$ \\
\hline \hline
\end{tabular}




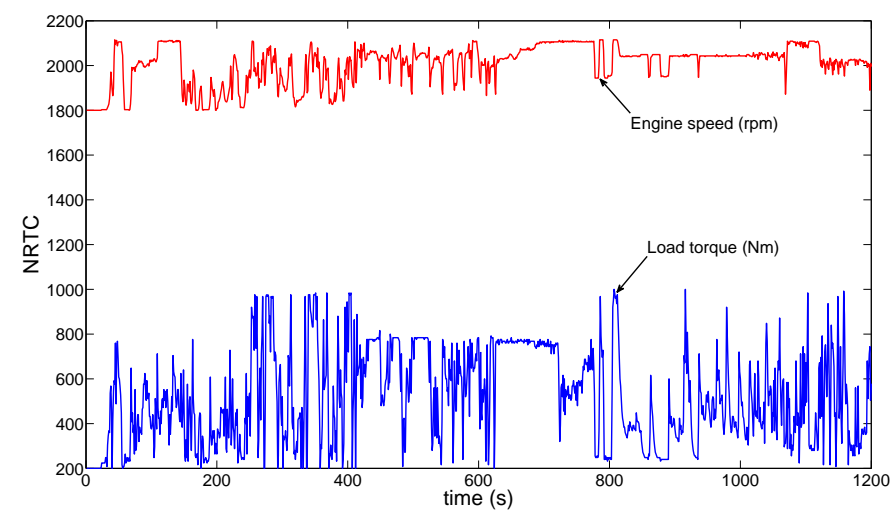

(a) Non-road transient cycle

Fig. 11. Test transient cycles

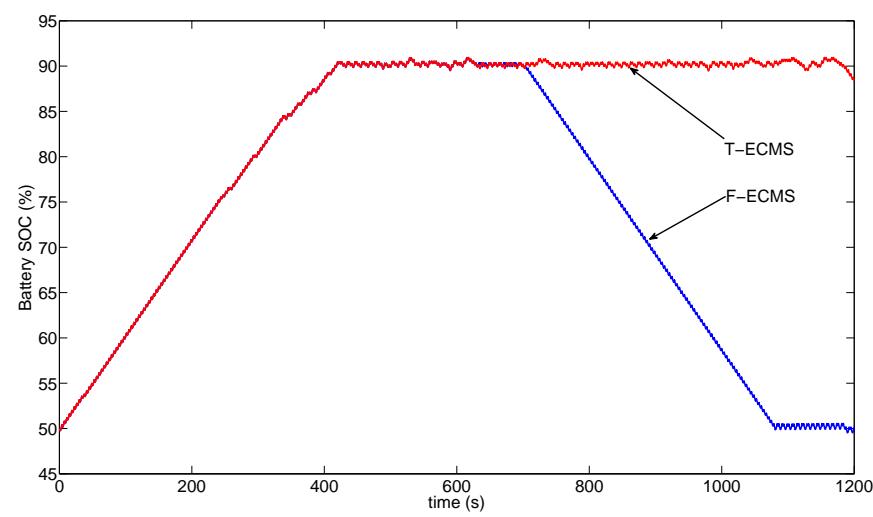

(a) Battery SOC under NRTC

Fig. 12. Comparison of the battery SOC sustainability

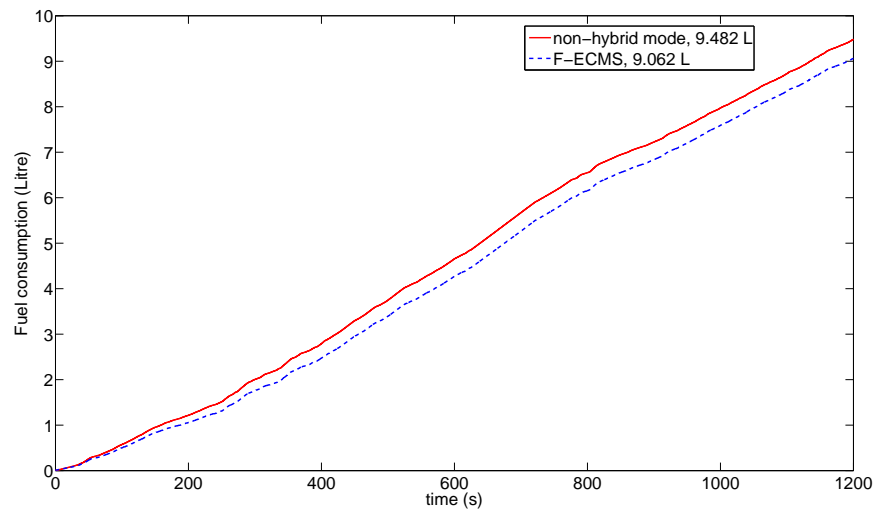

(a) Fuel consumption under NRTC

Fig. 13. Comparison of the fuel consumption

cost factor is calculated by

$$
s(t, \mathrm{SOC})=p(t) s_{\mathrm{chg}}+(1-p(t)) s_{\mathrm{dis}}
$$

with the probability $p(t)$ resulting from

$$
p(t)=\frac{E_{e}(t)+\lambda_{d c_{-} \max } / \eta_{e}\left(E_{m}-E_{m}\left(t_{f}\right)\right)}{\left(\lambda_{d c_{-} \max } / \eta_{e}+\lambda_{d c_{-} \min } \eta_{e}\right)\left(E_{m}-E_{m}\left(t_{f}\right)\right)}
$$

where

$$
\eta_{e}=\sqrt{s_{\mathrm{dis}} / s_{\mathrm{chg}}}
$$

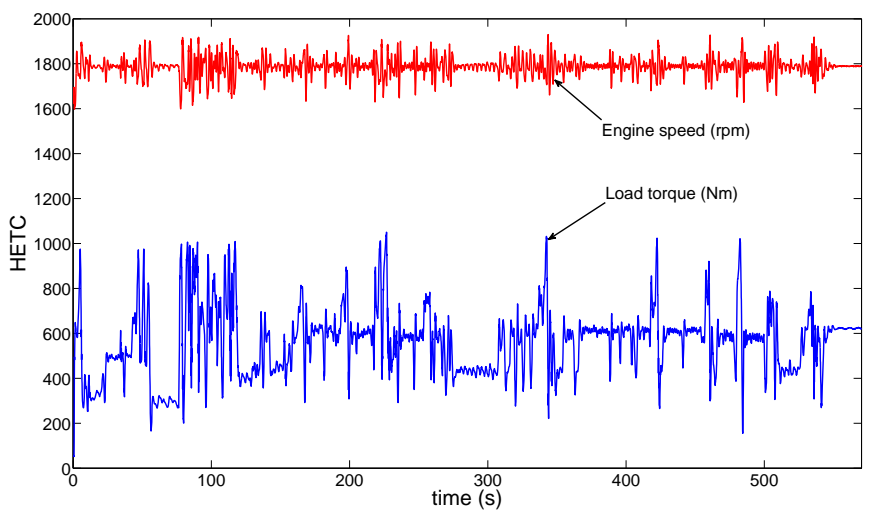

(b) Hydraulic excavation transient cycle

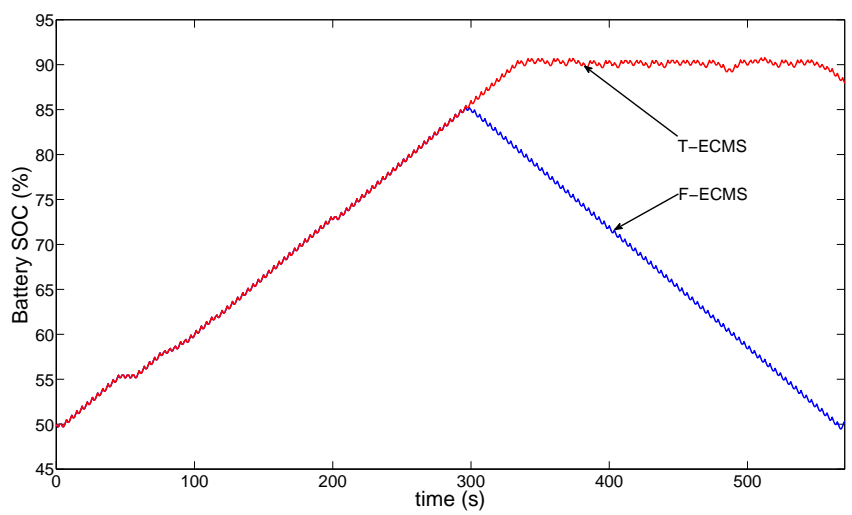

(b) Battery SOC under HETC

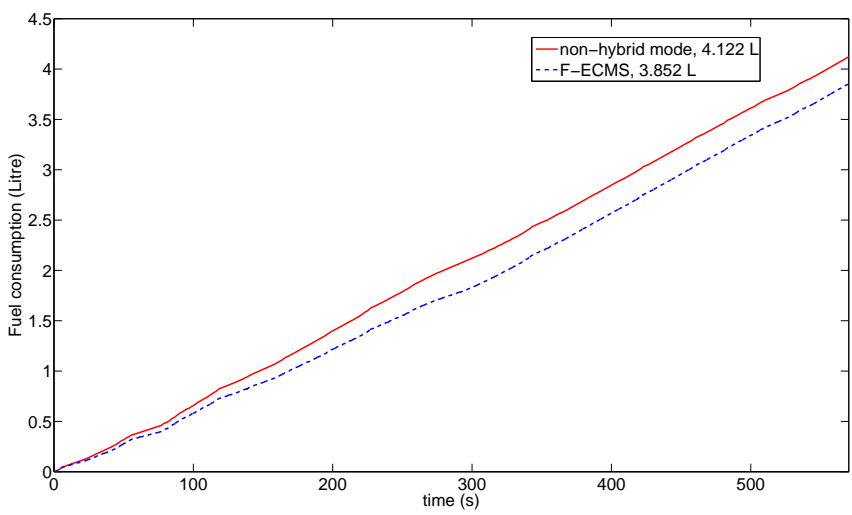

(b) Fuel consumption under HETC

The F-ECMS method shows good performance in regulating the $\operatorname{SOC}(t)$. In the NRTC test, the battery is continuously charged within $[0 \mathrm{~s}, 400 \mathrm{~s}]$, until the $\mathrm{SOC}_{\max }$ is achieved. Because of the regulation of (35), the $\mathrm{SOC}(t)$ is maintained at a steady value within $[420 \mathrm{~s}, 700 \mathrm{~s}]$ and does not exceed the allowed limits. From $700 \mathrm{~s}$, the $\mathrm{SOC}(t)$ is decreasing, until $\mathrm{SOC}(t)=\mathrm{SOC}\left(t_{0}\right)$ is attained at $1080 \mathrm{~s}$. In the final period of NRTC, the $\operatorname{SOC}(t)$ slightly oscillated around $\operatorname{SOC}\left(t_{0}\right)$ due to the real-time computation of $s(t, \mathrm{SOC})$ with high sampling frequency. In the HETC test, the battery is charged to a peak 
TABLE V

PARAMETERS OF THE SUPERVISORY CONTROLLER

\begin{tabular}{ll}
\hline \hline$\lambda_{d c_{-} \max }$ & 0.5 \\
$\lambda_{d c_{-} \min }$ & -0.5 \\
$\chi_{v g t_{-} \max }$ & 0.8 \\
$\chi_{v g t_{-} \min }$ & 0.4 \\
$\chi_{\text {egr_max }}$ & 0.2 \\
$\chi_{\text {egr_min }}$ & 0.05 \\
$\mathrm{SOC}_{\max }$ & $90 \%$ \\
$\mathrm{SOC}_{\min }$ & $10 \%$ \\
$\mathrm{SOC}\left(t_{0}\right)$ & $50 \%$ \\
$\Delta \lambda_{d c}$ & 0.25 \\
$\Delta \chi_{v g t}$ & 0.05 \\
$\Delta \chi_{\text {egr }}$ & 0.025 \\
\hline \hline
\end{tabular}
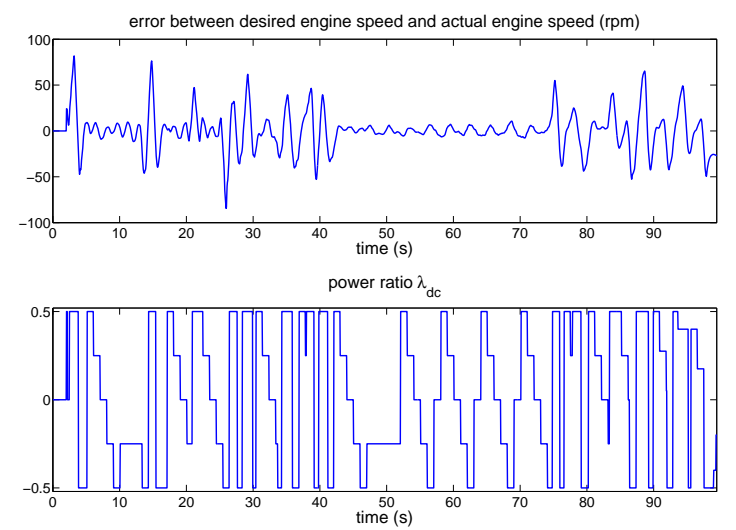

Fig. 14. Demonstration of the $\lambda_{d c}$ tuning process during [230s, 329s] of the HETC

value of about $85 \%$ at around $300 \mathrm{~s}$ then declines to $\operatorname{SOC}\left(t_{0}\right)$ at the terminal point of testing. This shows the effectiveness of fuzzy tuning on $s(t, \mathrm{SOC})$ and therefore demonstrates a good adaptive performance on the sustainable usage of the electrical energy. It is convenient to generalize the F-ECMS to the other cycles by tuning the parameter values set using the membership functions. The performance of regulating $\mathrm{SOC}(t)$ using the T-ECMS is relatively weaker. Owing to the deterministic probability model employed, the $\mathrm{SOC}(t)$ increases gradually and decreases only at the very end of testing, thus the constraint on the battery usage sustainability is not satisfied. The T-ECMS is more effective in test cycles with rather slow dynamics such as the new European driving cycle (NEDC), which has been verified in [29].

Due to the T-ECMS being unable to satisfy the boundary condition on the battery SOC (26), it is unreasonable to compare the T-ECMS with the F-ECMS on fuel economy optimization. The comparisons of the fuel economy using FECMS and non-hybrid mode approaches under the NRTC and the HETC are depicted in Fig. 13(a) and Fig. 13(b), respectively, while the $H_{\mathrm{LHV}}$ is set as $42.68 \mathrm{MJ} / \mathrm{kg}$. The fuel efficiency benefit with F-ECMS is significant, with the fuel economy improvements of $4.43 \%$ and $6.44 \%$ on the two specified test cycles, respectively. The F-ECMS is more adaptive in calculating the $p(t)$ than the T-ECMS which uses a deterministic model, so the F-ECMS achieves better fuel economy optimization. The improvement in fuel economy in the HETC is better than in NRTC because the HETC is the test cycle with fixed engine speed. The oscillation on the speed in Fig. 11(b) is due to the hardware coupling between the load and the engine. Furthermore, the dynamics of the load in HETC is slower than that in the NRTC, which means load torque following in the HETC is achieved more easily than in the NRTC. The ECMS algorithm works better under steady state conditions than under transient conditions because of the mechanical inertia of the vehicle.

As an illustration, the tuning process of $\lambda_{d c}$ during [230s, 329s] of the HETC is shown in Fig. 14. In transient states, at the instant the engine power demand is increasing, the error between the desired engine speed and actual engine speed is positive and increasing. Correspondingly, EMG 1 and EMG 2 work in motoring mode to assist the engine. When the engine power demand is decreasing, the error between the desired engine speed and actual engine speed is negative and decreasing. As a result, EMG 1 and EMG 2 work in generating mode to harvest the energy.

\section{CONCLUSION}

In this paper, an intelligent real-time energy management strategy called F-ECMS is proposed for heavy duty HEVs. Through analysis of both of the power flow in a HEV and the air path system model of a diesel engine, the necessity of optimizing the electric motor power, VGT vane opening, and EGR valve opening are elaborated. In the proposed method, a rolling on-line optimization method is applied to finding the best setting of the three control variables. By defining a cost function in terms of weighted fuel power and electrical power, the on-line optimization problem is formulated as the minimization of the cost function in each sampling period. To realize the sustainable usage of the battery, a fuzzy rule-based approach is developed for tuning the cost factor within the cost function. Both the battery SOC deviation and the task progress are used to calculate the rational value of the cost factor. The proposed F-ECMS is evaluated under NRTC and HETC on the $\mathrm{CAT}^{\circledR} \mathrm{C} 15$ diesel engine model, with a fuel economy improvement of $4.43 \%$ and $6.44 \%$, respectively. Compared with traditional T-ECMS, F-ECMS represents better performance in maintaining the battery sustainability. The improvements result from the fuzzy model employed in F-ECMS shows greater adaptability in tuning the cost factor under test cycles with fast dynamics.

As a topic of the future work, the calibration effort in designing the fuzzy logic rules within the F-ECMS should be improved. In the near future, four research issues need to be expanded: (1) the integration with a road condition preview method; (2) controlling EMG 1 and EMG 2 separately; (3) establishing a hierarchical framework including supervisory control and lower level control; and (4) the application of the proposed F-ECMS in real experimental tests.

\section{REFERENCES}

[1] Office of the Press Secretary. (2011) White house announces first ever oil savings standards for heavy duty trucks, buses. The White House. Washington DC, USA. [Online]. Available: http://www.whitehouse.gov/the-press-office/2011/08/09/ white-house-announces-first-ever-oil-savings-standards-heavy-duty-trucks 
[2] J. M. Liu and H. E. Peng, "Modeling and control of a power-split hybrid vehicle," IEEE Transactions on Control Systems Technology, vol. 16, no. 6, pp. 1242-1251, 2008.

[3] F. R. Salmasi, "Control strategies for hybrid electric vehicles: Evolution, classification, comparison, and future trends," IEEE Transactions on Vehicular Technology, vol. 56, no. 5, pp. 2393-2404, 2007.

[4] J. M. Miller, "Hybrid electric vehicle propulsion system architectures of the e-CVT type," IEEE Transactions on Power Electronics, vol. 21, no. 3, pp. 756-767, 2006

[5] M. Ehsani, Y. Gao, and J. M. Miller, "Hybrid electric vehicles: Architecture and motor drives," Proceedings of the IEEE, vol. 95, no. 4, pp. 719-728, 2007.

[6] J. S. Won, R. Langari, and M. Ehsani, "An energy management and charge sustaining strategy for a parallel hybrid vehicle with CVT," IEEE Transactions on Control Systems Technology, vol. 13, no. 2, pp. 313320, 2005.

[7] S. Adhikari, S. K. Halgamuge, and H. C. Watson, "An online powerbalancing strategy for a parallel hybrid electric vehicle assisted by an integrated starter generator," IEEE Transactions on Vehicular Technology, vol. 59, no. 6, pp. 2689-2699, 2010.

[8] S. Bogosyan, M. Gokasan, and D. J. Goering, "A novel model validation and estimation approach for hybrid serial electric vehicles," IEEE Transactions on Vehicular Technology, vol. 56, no. 4, pp. 1485-1497, 2007.

[9] S. Barsali, C. Miulli, and A. Possenti, "A control strategy to minimize fuel consumption of series hybrid electric vehicles," IEEE Transactions on Energy Conversion, vol. 19, no. 1, pp. 187-195, 2004.

[10] F. U. Syed, M. L. Kuang, J. Czubay, and H. Ying, "Derivation and experimental validation of a power-split hybrid electric vehicle model," IEEE Transactions on Vehicular Technology, vol. 55, no. 6, pp. 17311747,2006

[11] N. Kim, S. Cha, and H. Peng, "Optimal control of hybrid electric vehicles based on pontryagin's minimum principle," IEEE Transactions on Control Systems Technology, vol. 19, no. 5, pp. 1279-1287, 2011.

[12] C. C. Chan, A. Bouscayrol, and K. Chen, "Electric, hybrid, and fuel-cell vehicles: Architectures and modeling," IEEE Transactions on Vehicular Technology, vol. 59, no. 2, pp. 589-598, 2010.

[13] D. H. Shin, B. H. Lee, J. B. Jeong, H. S. Song, and H. J. Kim, "Advanced hybrid energy storage system for mild hybrid electric vehicles," International Journal of Automotive Technology, vol. 12, no. 1, pp. 125-130, 2011.

[14] D. W. Gao, C. Mi, and A. Emadi, "Modeling and simulation of electric and hybrid vehicles," Proceedings of the IEEE, vol. 95, no. 4, pp. 729745, 2007.

[15] S. Pekarek, K. Uthaichana, S. Bengea, R. DeCarlo, and M. Zefran, "Modeling of an electric drive for a HEV supervisory level power flow control problem," in Proceedings of the IEEE Conference on Vehicle Power and Propulsion, 2005, pp. 396-401.

[16] A. Kleimaier and D. Schroder, "Optimization strategy for design and control of a hybrid vehicle," in Proceedings of the 6th International Workshop on Advanced Motion Control, 2000, pp. 459-464.

[17] H. Banvait, S. Anwar, and Y. Chen, "A rule-based energy management strategy for plug-in hybrid electric vehicle (PHEV)," in Proceedings of the American Control Conference, 2009, pp. 3938-3943.

[18] F. U. Syed, M. L. Kuang, M. Smith, S. Okubo, and H. Ying, "Fuzzy gainscheduling proportional-integral control for improving engine power and speed behavior in a hybrid electric vehicle," IEEE Transactions on Vehicular Technology, vol. 58, no. 1, pp. 69-84, 2009.

[19] H. D. Lee, E. S. Koo, S. K. Sul, and J. S. Kim, "Torque control strategy for a parallel-hybrid vehicle using fuzzy logic," IEEE Industry Applications Magazine, vol. 6, no. 6, pp. 33-38, 2000.

[20] B. Mashadi and S. A. M. Emadi, "Dual-mode power-split transmission for hybrid electric vehicles," IEEE Transactions on Vehicular Technology, vol. 59, no. 7, pp. 3223-3232, 2010.

[21] B. M. Baumann, G. Washington, B. C. Glenn, and G. Rizzoni, "Mechatronic design and control of hybrid electric vehicles," IEEE-ASME Transactions on Mechatronics, vol. 5, no. 1, pp. 58-72, 2000.

[22] P. Pisu and G. Rizzoni, "A comparative study of supervisory control strategies for hybrid electric vehicles," IEEE Transactions on Control Systems Technology, vol. 15, no. 3, pp. 506-518, 2007.

[23] C. C. Lin, H. Peng, J. W. Grizzle, and J. M. Kang, "Power management strategy for a parallel hybrid electric truck," IEEE Transactions on Control Systems Technology, vol. 11, no. 6, pp. 839-849, 2003.

[24] M. Koot, J. Kessels, B. de Jager, W. Heemels, P. P. J. van den Bosch, and M. Steinbuch, "Energy management strategies for vehicular electric power systems," IEEE Transactions on Vehicular Technology, vol. 54, no. 3, pp. 771-782, 2005
[25] S. Stockar, V. Marano, M. Canova, G. Rizzoni, and L. Guzzella, "Energy-optimal control of plug-in hybrid electric vehicles for realworld driving cycles," IEEE Transactions on Vehicular Technology, vol. 60, no. 7, pp. 2949-2962, 2011.

[26] I. Kolmanovsky, I. Siverguina, and B. Lygoe, "Optimization of powertrain operating policy for feasibility assessment and calibration: Stochastic dynamic programming approach," in Proceedings of the American Control Conference, 2002, pp. 1425-1430.

[27] S. J. Moura, H. K. Fathy, D. S. Callaway, and J. L. Stein, "A stochastic optimal control approach for power management in plug-in hybrid electric vehicles," IEEE Transactions on Control Systems Technology, vol. 19, no. 3, pp. 545-555, 2011.

[28] E. D. Tate and S. P. Boyd, "Finding ultimate limits of performance for hybrid electric vehicles," in Proceedings of the Future Transportation Technology Conference, 2000, pp. 2000-01-3099.

[29] A. Sciarretta, M. Back, and L. Guzzella, "Optimal control of parallel hybrid electric vehicles," IEEE Transactions on Control Systems Technology, vol. 12, no. 3, pp. 352-363, 2004.

[30] C. Musardo, G. Rizzoni, Y. Guezennec, and B. Staccia, "A-ECMS: An adaptive algorithm for hybrid electric vehicle energy management," in Proceedings of the Joint IEEE Conference on Decision and Control \& European Control Conference, 2005, pp. 509-524.

[31] A. Sciarretta and L. Guzzella, "Control of hybrid electric vehicles," IEEE Control Systems Magazine, vol. 27, no. 2, pp. 60-70, 2007.

[32] L. Guzzella and A. Sciarretta, Vehicle Propulsion System: Introduction to Modeling and Optimization. Berlin, Germany: Springer, 2005.

[33] V. Sezer, M. Gokasan, and S. Bogosyan, "A novel ECMS and combined cost map approach for high-efficiency series hybrid electric vehicles," IEEE Transactions on Vehicular Technology, vol. 60, no. 8, pp. 35573570, 2011.

[34] P. Rodatz, G. Paganelli, A. Sciarretta, and L. Guzzella, "Optimal power management of an experimental fuel cell/supercapacitor-powered hybrid vehicle," Control Engineering Practice, vol. 13, no. 1, pp. 41-53, 2005.

[35] H. Borhan, A. Vahidi, A. M. Phillips, M. L. Kuang, I. Kolmanovsky, and S. D. Cairano, "MPC-based energy management of a power-split hybrid electric vehicle," IEEE Transactions on Control Systems Technology, vol. 19, no. 99, pp. 1-11, 2011.

[36] H. A. Borhan, A. Vahidi, A. M. Phillips, M. L. Kuang, and I. V. Kolmanovsky, "Predictive energy management of a power-split hybrid electric vehicle," in Proceedings of the American Control Conference, 2009, pp. 3970-3976.

[37] H. A. Borhan and A. Vahidi, "Model predictive control of a power-split hybrid electric vehicle with combined battery and ultracapacitor energy storage," in Proceedings of the American Control Conference, 2010, pp. 5031-5036.

[38] H. A. Borhan, C. Zhang, A. Vahidi, A. M. Phillips, M. L. Kuang, and S. Di Cairano, "Nonlinear model predictive control for power-split hybrid electric vehicles," in Proceedings of the IEEE Conference on Decision and Control, 2010, pp. 4890-4895.

[39] C. Zhang, A. Vahidi, P. Pisu, X. P. Li, and K. Tennant, "Role of terrain preview in energy management of hybrid electric vehicles," IEEE Transactions on Vehicular Technology, vol. 59, no. 3, pp. 1139-1147, 2010.

[40] L. Serrao, S. Onori, and G. Rizzoni, "A comparative analysis of energy management strategies for hybrid electric vehicles," Journal of Dynamic Systems, Measurement, and Control, vol. 133, no. 3, pp. 031012 1-9, 2011.

[41] M. J. Van Nieuwstadt, I. V. Kolmanovsky, P. E. Moraal, A. Stefanopoulou, and M. Jankovic, "EGR-VGT control schemes: Experimental comparison for a high-speed diesel engine," IEEE Control Systems Magazine, vol. 20, no. 3, pp. 63-79, 2000.

[42] A. Plianos and R. K. Stobart, "Nonlinear airpath control of modern diesel powertrains: a fuzzy systems approach," International Journal of Systems Science, vol. 42, pp. 263-275, 2011.

[43] M. Jankovic and I. Kolmanovsky, "Constructive lyapunov control design for turbocharged diesel engines," IEEE Transactions on Control Systems Technology, vol. 8, no. 2, pp. 288-299, 2000.

[44] P. Ortner and L. Del Re, "Predictive control of a diesel engine air path," IEEE Transactions on Control Systems Technology, vol. 15, no. 3, pp. 449-456, 2007

[45] H. J. Ferreau, P. Ortner, P. Langthaler, L. Del Re, and M. Diehl, "Predictive control of a real-world diesel engine using an extended online active set strategy," Annual Reviews in Control, vol. 31, no. 2, pp. 293-301, 2007.

[46] J. Wahlstrom, L. Eriksson, and L. Nielsen, "EGR-VGT control and tuning for pumping work minimization and emission control," IEEE 
Transactions on Control Systems Technology, vol. 18, no. 4, pp. 993 1003, 2010.

[47] F. Willems, S. Spronkmans, and J. Kessels, "Integrated powertrain control to meet low $\mathrm{CO} 2$ emission for a hybrid distribution truck with SCR-deNOx system," in Proceedings of the ASME Dynamics systems and Control Conference, 2011, pp. 396-401.

[48] F. Willems, F. Kupper, and R. Cloudt, "Integrated powertrain control for optimal $\mathrm{CO}_{2}-\mathrm{NO}_{x}$ tradeoff in an euro-vi diesel engine with waste heat recovery system," in Proceedings of the American Control Conference, 2012, pp. 1296-1301.

[49] D. Kum, H. Peng, and N. Bucknor, "Optimal energy and catalyst temperature management of plug-in hybrid electric vehicles for minimum fuel consumption and tail-pipe emissions," IEEE Transactions on Control Systems Technology, vol. 21, no. 1, pp. 14-26, 2013.

[50] R. Kroeze and P. Krein, "Electrical battery model for use in dynamic electric vehicle simulations," in Proceedings of the Power Electronics Specialists Conference, 2008, pp. 1336-1342.

[51] H. Chan and D. Sutanto, "A new battery model for use with battery energy storage systems and electric vehicles power systems," in Proceedings of the IEEE Power Engineering Society Winter Meeting, 2000, pp. 470-475.

[52] A. Rotenberg, D. Vahidi and I. Kolmanovsky, "Ultracapacitor assisted powertrains: Modeling, control, sizing, and the impact on fuel economy," IEEE Transactions on Control Systems Technology, vol. 19, no. 3, pp. 576-589, 2011.

[53] A. G. Stefanopoulou, I. Kolmanovsky, and J. S. Freudenberg, "Control of variable geometry turbocharged diesel engines for reduced emissions," IEEE Transactions on Control Systems Technology, vol. 8, no. 4, pp. 733-745, 2000.

[54] L. Serrao, S. Onori, and G. Rizzoni, "ECMS as a realization of pontryagin's minimum principle for HEV control," in Proceedings of the American Control Conference, June 2009, pp. 3964-3969.

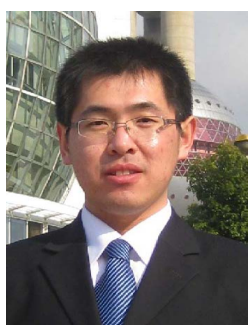

Dezong Zhao (M'12) received the B.S. and M.S degrees from the School of Control Science and Engineering, Shandong University, Jinan, China, in 2003 and 2006, respectively, and the Ph.D. degree from the Department of Automation, Tsinghua University, Beijing, China, in 2010.

$\mathrm{He}$ is currently a Research Associate with the Department of Aeronautical and Automotive Engineering, Loughborough University, Loughborough, U.K. His current research interests include nonlinear control on modern engines, energy recovery systems, and hybrid electric vehicles.

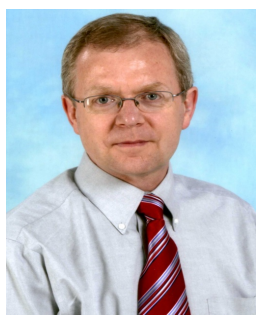

Richard Stobart (M'93) received the B.S. degree (with first-class honors) in mechanical engineering from the University of Cambridge, Cambridge, U.K., in 1979.

From 2001 to 2007, he was a Professor of automotive engineering with the University of Sussex, Brighton, U.K., where he was also the Head of Engineering and Design from 2003 to 2006. From 2008 to 2011, he was the Head of the Department of Aeronautical and Automotive Engineering, Loughborough University, Loughborough, U.K., where he was also a member of the Engineering Faculty Board. He is currently a Professor of powertrain systems with Loughborough University and the Technical Director of the Caterpillar-funded Innovation and Research Centre, Loughborough University, Loughborough, U.K.

Prof. Stobart was a member of the team who, in 1997, was the recipient of the Arthur D. Little Ketteringham Prize. He was elected as a Fellow of the U.K. Institution of Mechanical Engineers in 2000. He completed his term as Chair of the Powertrain, Fuels, and Lubricants Activity of SAE International in 2007. He is currently the Chair of the SAE International U.K. Section.

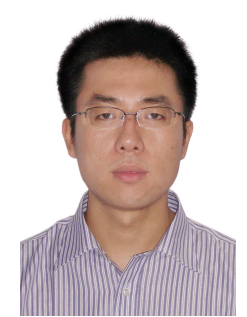

Guangyu Dong received the M.S. degree in mechanical engineering from Jilin University, Changchun, China, in 2005 and the Ph.D. degree in automotive engineering from Tongji University, Shanghai, China, in 2010.

From 2010 to 2013 , he held a postdoctoral position at Loughborough University, Loughborough, U.K. He is currently a Research Fellow with the Sir Harry Ricardo Laboratories, Centre for Automotive Engineering, University of Brighton, Brighton, U.K. His current research focuses on engine thermodynamic cycle control and combustion kinetics.

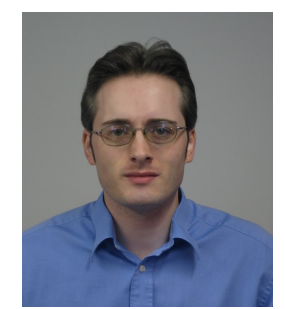

Edward Winward received the B.S. degree in automotive engineering in 2003 and the Ph.D degree in the study of diesel engine exhaust soot physiochemical properties in 2013 from Loughborough University, Loughborogh, U.K.

Since 2007, he has been a Research Associate with Loughborough University. Since 2009, he has been working in the Control and Reliability Group who experimentally investigated model-based air and fuel path engine controls, and in his present work, he is experimentally investigating the microhybridization and downspeeding of a medium-duty diesel engine through electrification of the turbocharger. 